\title{
Acoustical Behavior of Hybrid Composite Sandwich Panels
}

\section{PATINHA Sérgio ${ }^{1, \text { a }}$, CUNHA Fernando ${ }^{1}$, FANGUEIRO Raul $^{1, b}$, RANA Sohel ${ }^{1}$ and PREGO Fernando ${ }^{2}$}

\author{
${ }^{1}$ Fibrous Materials Research Group, School of Engineering, University of Minho, \\ Guimarães, Portugal \\ ${ }^{2}$ Sociedade de Construções, Guimarães, Portugal \\ asergiopatinha@civil.uminho.pt, ${ }^{b}$ rfangueiro@civil.uminho.pt
}

\begin{abstract}
Keywords: Acoustic Insulation, Sandwich Panels, Hybrid Composites.
\end{abstract}
\begin{abstract}
This paper deals with the characterization of acoustic insulation behaviour of hybrid sandwich composite panels for application in modular house construction. These sandwich panels are a sustainable, light-weight and durable solution, since are based on natural fibers structure impregnated with a thermosetting polymer. In this way, three different types of hybrid composite panels containing polyurethane core and laminated composite skins were produced and analyzed, varying the composition of laminates. The composite laminates of the prototypes were produced using a vacuum infusion technique and were composed of glass and jute fibers, impregnated with a polyester resin. The solutions developed were compared with a standard, composed of plasterboards having different thicknesses and used for thermal and acoustic insulation. Acoustic insulation characterization was performed on specimens with $220 \times 220 \mathrm{~mm}$ size in a sound proof acoustic chamber. The tested sandwich panels showed promising results; however, their overall performance was lower as compared to the performance of standard solutions used for comparison. Nevertheless, the specific acoustic insulation performance, i.e. sound reduction per unit mass of material for the developed sandwich panels was significantly higher as compared to the standard materials, indicating better suitability of this innovative solution for light-weight construction and modular housing.
\end{abstract}

\section{Introduction}

In current times, Fibre Reinforced Plastics (FRPs) have allowed the development of alternative solutions for construction industries with several advantages such as light weight, durability, high strength / weight ratio and corrosion resistance, among others. These advantages made it possible to apply these materials extensively in construction in various situations including strengthening and rehabilitation of structures, construction of bridges and other precast elements such as profiles and panels for construction [1].

Due to these features and industrialized process, FRP materials can also be applied in more efficient building systems such as modular housing. As an alternative to the traditional construction, this type of construction, can provide construction elements with increased quality, producing less wastes due to a more efficient construction process [2]. Comfort, performance as well as sound and thermal insulation in buildings are currently the most desirable needs for the modern construction industry [3]. In this work, the acoustical behavior of a hybrid sandwich panel is studied. These panels were developed through a modular construction methodology, and at same time as a sustainable construction solution, based on natural fiber composites. In this way, it has been possible to allow the sustainability of the natural fibers, with their high-strength and low-weight to provide an alternative sandwich panel to build internal partition walls, in a cost-efficient way.

Therefore, in order to apply these hybrid panels in the construction industry, is necessary to fully understand their acoustical behavior. In this way, many researchers have focused on the mechanism of sound transmission, particularly through the development of complex models that relate the 
physical and dimensional properties of sandwich composites to sound insulation [4]. Some of these researchers have dedicated their efforts to the development of optimization algorithms for sandwich panels [5,6]. These algorithms have also been applied to optimize the composition of sandwich panels with cork cores for application in the aerospace industry, [7]. Also, optimization of sound insulation at low frequencies for sandwich panels containing honeycomb cores have been performed for applying these materials in construction industry [8]. However, besides obtaining in-depth knowledge on the acoustic behavior of composite materials, it is also necessary to directly compare the performance of novel construction materials with the standard solutions which are already in use in the construction industry. According to the author's knowledge, there are no studies that directly compare the acoustic insulation performance of sandwich composite panels with traditional solutions used for interior or exterior partitions.

Therefore, the present research work is focused on the investigation of acoustic insulation performance of a wide range of sandwich composite panels and comparison of their performance with the standard construction solutions.

\section{Materials}

In the present work, hybrid composite panels were developed to combine strength and lightness (below $10 \mathrm{~kg} / \mathrm{m}^{2}$ ) with sustainability in one single solution. The panels were developed in a sandwich-type structure (Figure 1), composed of hybrid composite laminate panels on both sides, glued to a core of extruded polyurethane (XPS). The function of the composite laminate panels was to resist the bending and impact stresses, while the XPS core was responsible for providing thermal and acoustic insulation properties as well as resistance to applied shear stresses. [9]

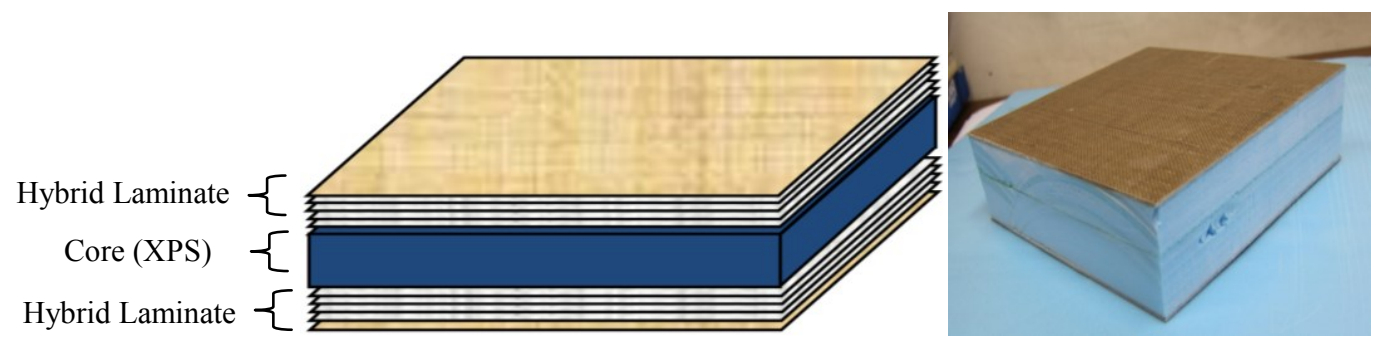

Fig. 1: Scheme diagram (left side) and picture (right side) of the developed hybrid composite panel

The hybrid composite panels were developed from several layers of fibrous reinforcements impregnated with a thermosetting resin, using "vacuum infusion" technique [10]. Since in these composite laminates or layers, both natural (jute fiber) and synthetic (fiberglass) fibres were used, they are designated as hybrid composite laminates. The physical and mechanical properties of these fibrous reinforcements are listed in Table 1.

These fibrous reinforcements were impregnated with an isophthalic polyester resin along with 2 (\%) of hardener and $0.2(\%)$ of accelerator. The characteristics of the used resin are listed in Table 2.

The impregnation of fibrous reinforcements was carried out using a vacuum infusion process (Figure 2). This process consists of placing the fibrous reinforcements over a glass plate which was hermetically sealed with a vacuum bag containing two output tubes. One of these outlet tubes was connected to a vacuum pump that put negative pressure in the vacuum bag resulting in filling of the resin in the vacuum bag through the second tube.

After impregnation of fibrous reinforcements, and curing of the resin, it was possible to obtain natural and synthetic fibre composites with the physical and mechanical properties presented in Table 3. 
Table 1: Fiber reinforcement characteristics

\begin{tabular}{|c|c|c|c|c|c|c|c|}
\hline $\begin{array}{c}\text { Fibrous } \\
\text { Reinforcement }\end{array}$ & Fiber & Visual Aspect & $\begin{array}{c}\text { Weight by } \\
\text { surface area } \\
{\left[\mathrm{g} / \mathrm{m}^{2}\right]}\end{array}$ & $\begin{array}{c}\text { Thickness } \\
{[\mathrm{mm}]}\end{array}$ & Orientation & $\begin{array}{l}\text { Strength } \\
{[\mathrm{N} / \mathrm{cm}]}\end{array}$ & $\begin{array}{c}\varepsilon_{\text {rupture }} \\
{[\%]}\end{array}$ \\
\hline \multirow{2}{*}{$\mathrm{T} 2$} & \multirow{2}{*}{ Jute } & & \multirow{2}{*}{398,3} & \multirow{2}{*}{1,2} & $0^{\circ}$ & 143,2 & 7,64 \\
\hline & & & & & $90^{\circ}$ & 109,2 & 3,54 \\
\hline \multirow{2}{*}{ T9 } & \multirow{2}{*}{ Glass } & & \multirow{2}{*}{304,3} & \multirow{2}{*}{0,57} & $0^{\circ}$ & 532,4 & 2,56 \\
\hline & & & & & $90^{\circ}$ & 522,8 & 2,74 \\
\hline
\end{tabular}

Table 2: Physical and mechanical properties of polyester resin used in this study

\begin{tabular}{|l|c|c|c|}
\hline Characteristics & Units & Standards & Values \\
\hline Distortional temperature & {$\left[{ }^{\circ} \mathrm{C}\right]$} & ASTM D-648 & $\begin{array}{c}90- \\
100\end{array}$ \\
\hline Water Absorption & {$[\%]$} & ASTM D-570 & 0,15 \\
\hline Tensile Strength & {$[\mathrm{MPa}]$} & ASTM D-638 & $50-70$ \\
\hline Flexural Strength & {$[\mathrm{MPa}]$} & ASTM D-790 & $\begin{array}{c}90- \\
120\end{array}$ \\
\hline Extension at failure & & & 3,5 \\
\hline
\end{tabular}
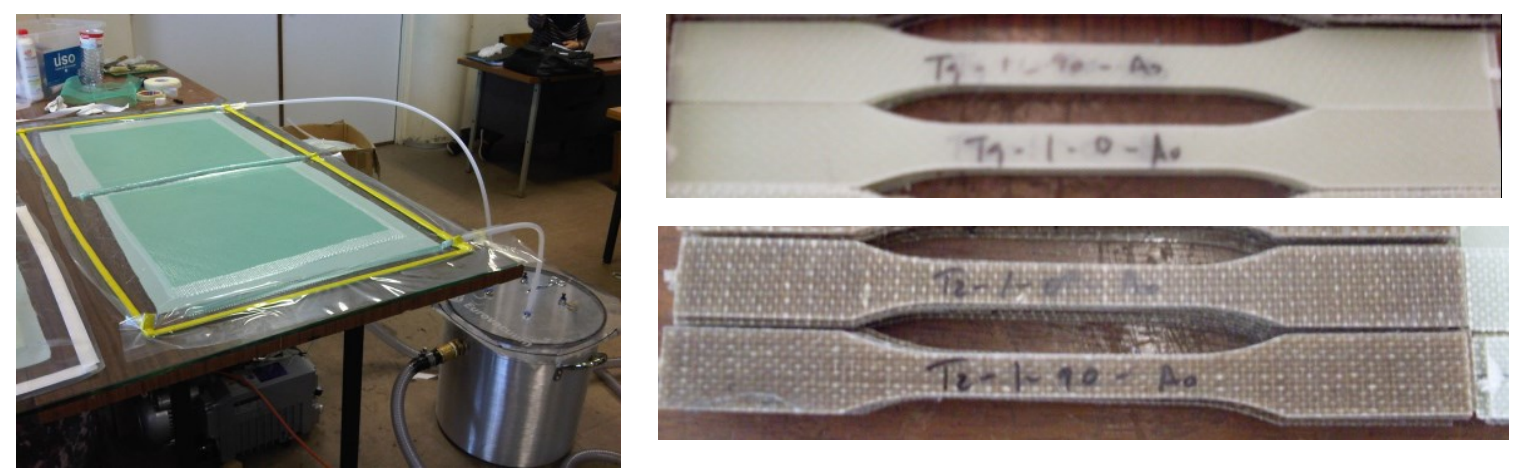

Fig. 2: Vacuum infusion process (left side), a polyester resin / jute fiber composite (top and rigth corner) and a polyester resin / fiberglass composite (bottom and rigth corner)

Table 3: Physical and mechanical properties of glass and jute fibre laminates.

\begin{tabular}{|c|c|c|c|c|c|c|c|c|}
\hline $\begin{array}{c}\text { Fibrous } \\
\text { Reinforcement } \\
\end{array}$ & Resin & $\begin{array}{l}\rho_{\text {compósite }} \\
{\left[\mathrm{g} / \mathrm{cm}^{3}\right]}\end{array}$ & $\mathrm{m}_{\text {fiber }} / \mathrm{m}_{\text {composite }}$ & $\mathrm{V}_{\text {fiber }} / \mathrm{V}_{\text {composite }}$ & Orientation & $\begin{array}{c}\sigma_{\text {rupture }} \\
{[\mathrm{MPa}]}\end{array}$ & $\begin{array}{c}\varepsilon_{\text {rupture }} \\
{[\%]}\end{array}$ & $\begin{array}{c}\mathrm{E} \\
{[\mathrm{MPa}]}\end{array}$ \\
\hline \multirow{2}{*}{$\mathrm{T} 2$} & \multirow{2}{*}{ Polyester } & \multirow{2}{*}{1,24} & \multirow{2}{*}{$31,4 \%$} & \multirow{2}{*}{$27,2 \%$} & $0^{\circ}$ & 39,2 & $2,80 \%$ & 1502 \\
\hline & & & & & $90^{\circ}$ & 44,7 & $4,20 \%$ & 1607 \\
\hline \multirow{2}{*}{ T9 } & \multirow{2}{*}{ Polyester } & \multirow{2}{*}{1,88} & \multirow{2}{*}{$65,5 \%$} & \multirow{2}{*}{$47,4 \%$} & $0^{\circ}$ & 352,9 & $1,75 \%$ & 16785 \\
\hline & & & & & $90^{\circ}$ & 324,6 & $2,02 \%$ & 14312 \\
\hline
\end{tabular}

Therefore, it was possible to combine different layers of fibrous reinforcements in order to obtain sandwich panels with distinct mechanical properties. To develop hybrid sandwich panels with desired characteristics, three different hybrid laminates were produced and analyzed as presented in the following scheme and Figure 3. :

- 2T9+T2 laminate: composed of 1 layer of T2 (jute) and 2 layers of T9 (Glass);

- 3T9+T2 laminate: composed of 1 layer of T2 (jute) and 3 layers of T9 (Glass);

- 4T9+T2 laminate: composed of 1 layer of T2 (jute) and 4 layers of T9 (Glass). 


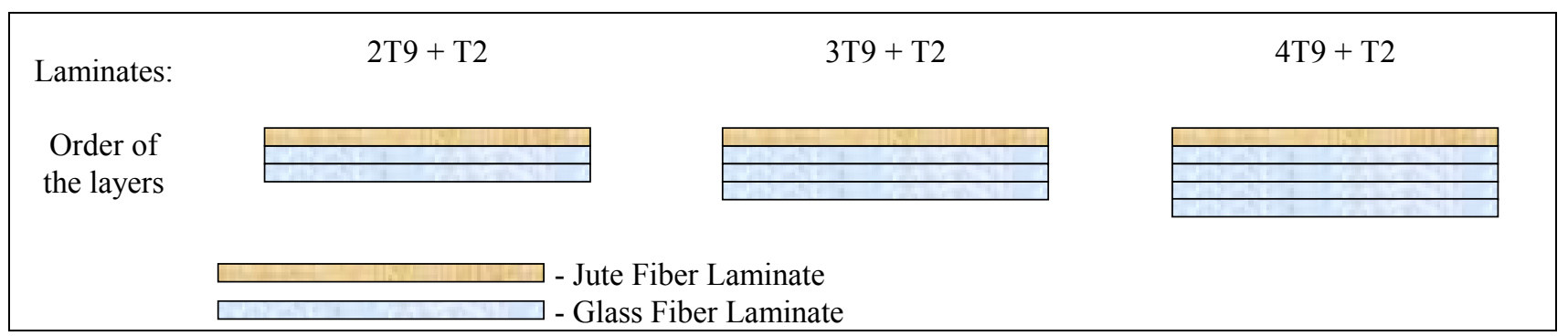

Fig. 3: Scheme showing composition of diferent hybrid laminates

Therefore, using the above combinations sandwich panels with different thicknesses were obtained, as detailed in Table 4. To produce these sandwich panels, different hybrid laminates were bonded with XPS core with $30 \mathrm{~kg} / \mathrm{m}^{3}$ density and compressive strength of $300 \mathrm{kPa}$ using $375 \mathrm{~g} / \mathrm{m}^{2}$ epoxy adhesive. The thickness of the panels was kept constant and it was set to $72 \mathrm{~mm}$. The three prototypes were analyzed and compared with the standard solutions. Special panels incorporating plasterboard were built, simulating a conventional dry type wall. Plasterboard used for this purpose had a thickness of $12.5 \mathrm{~mm}$ and a surface weight of $7.8 \mathrm{~kg} / \mathrm{m}^{2}$. The three plasterboard solutions developed and analyzed are presented in Table 4:

- "Plasterboard Panel + XPS": 72 millimeter panel composed of 2 layers of plasterboard insulated with a XPS core.

- "Plasterboard wall": Simple wall solution composed of 2 plasterboard plates connected by a bolt connection to a light steel profile, creating an interior air box.

- "Plasterboard Wall + Insulation": Plasterboard wall containing a mineral wood insulation layer of $30 \mathrm{~kg} / \mathrm{m}^{2}$.

The dimensional characteristics of the specimens are presented in Table 4 and Figure 4.

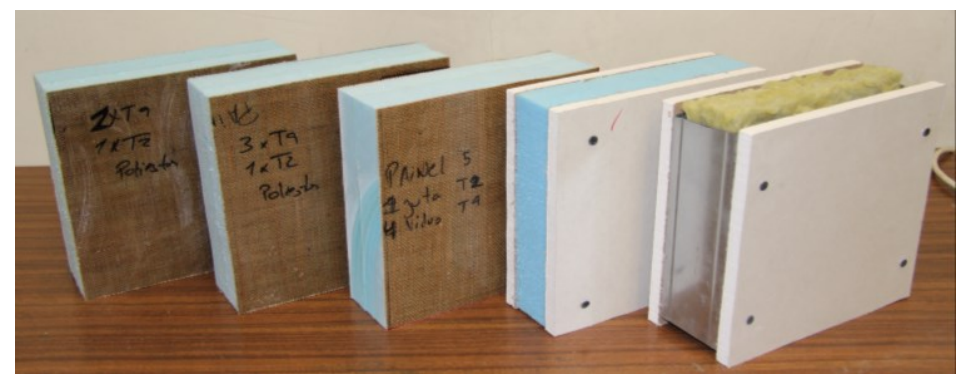

Fig. 4: Speciments (from left to rigth.): 2T9+T2, 3T9+T2, 4T9+T2, Plasterboard Pannel + XPS and Plasterboard Wall + Insulation;

Table 4: Details of various specimens developed within this study

\begin{tabular}{|c|c|c|c|c|c|}
\hline Sample & $\begin{array}{c}\text { Weight by surface } \\
\text { area } \\
{\left[\mathrm{kg} / \mathrm{m}^{2}\right]}\end{array}$ & $\begin{array}{c}\text { Total } \\
\text { Thickness } \\
{[\mathrm{mm}]}\end{array}$ & $\begin{array}{c}\text { Laminate } \\
\text { Thickness } \\
{[\mathrm{mm}]}\end{array}$ & $\begin{array}{c}\text { Insulation } \\
\text { Material }\end{array}$ & $\begin{array}{c}\text { Insulation } \\
\text { thickness } \\
{[\mathrm{mm}]}\end{array}$ \\
\hline Panel 2T9+T2 & 7,85 & 72 & 1,85 & XPS & 68,3 \\
\hline Panel 3T9+T3 & 7,93 & 72 & 2,20 & XPS & 67,4 \\
\hline Panel 4T9+T3 & 9,20 & 72 & 2,70 & XPS & 66,6 \\
\hline Plasterboard + XPS & 16,84 & 72 & $12,5^{*}$ & XPS & 47 \\
\hline Plasterboard wall & 20,33 & 95 & $12,5^{*}$ & None & - \\
\hline Plasterboard Wall + Insulation & 21,82 & 95 & $12,5^{*}$ & Rock Wool & - \\
\hline
\end{tabular}

*Note: the thickness values with "*” are related to the plasterboard thickness

The plasterboard solutions (standard solution) were included in this study as reference solutions since this material is widely used in lightweight construction. 


\section{Acoustic Characterization}

The characterization of acoustic insulation was performed on specimens having dimension of $220 \times 220 \mathrm{~mm}$ in a box made of composite material, which is acoustically isolated and built (Figure 5) in accordance with the specifications followed in the references (7) and (8). This box consists of:

- Sound Source: responsible for creating the noise;

- Holes for placement of sound level meters: available at different distances from the sound source;

- Slots for placement of specimens to ensure the fixation of samples and their positioning to known distances from the source.

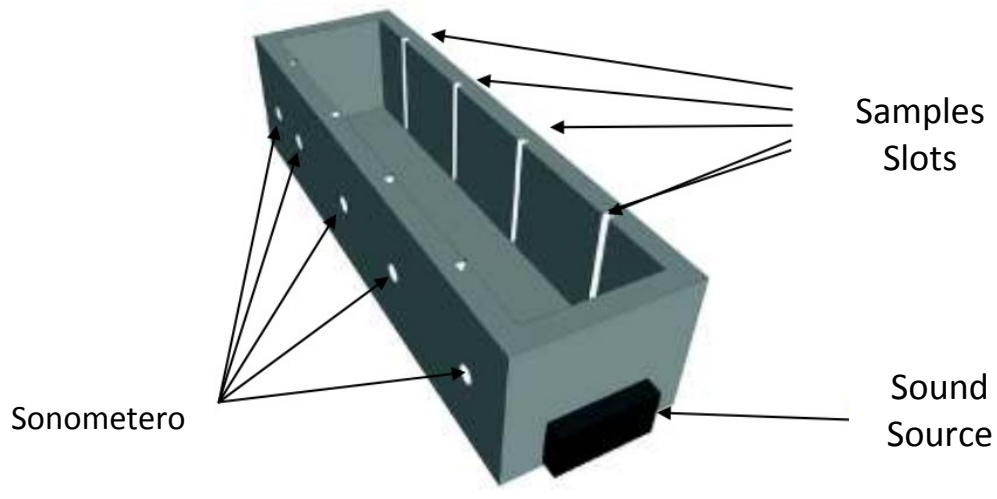

Fig. 5: Sound insulated box for noise reduction assessment [11]

The sound insulation was measured in terms of reducing audible noise by each sample, keeping the distance between the sample and the source of noise emission constant. Noise reduction was calculated by subtracting the reduction of the noise level obtained with and without the sample. Measurements were made using two sound level meters which measured the sound intensity before and after the samples (Figure 6). The sound was originated in a computer using an audio track with pink noise.
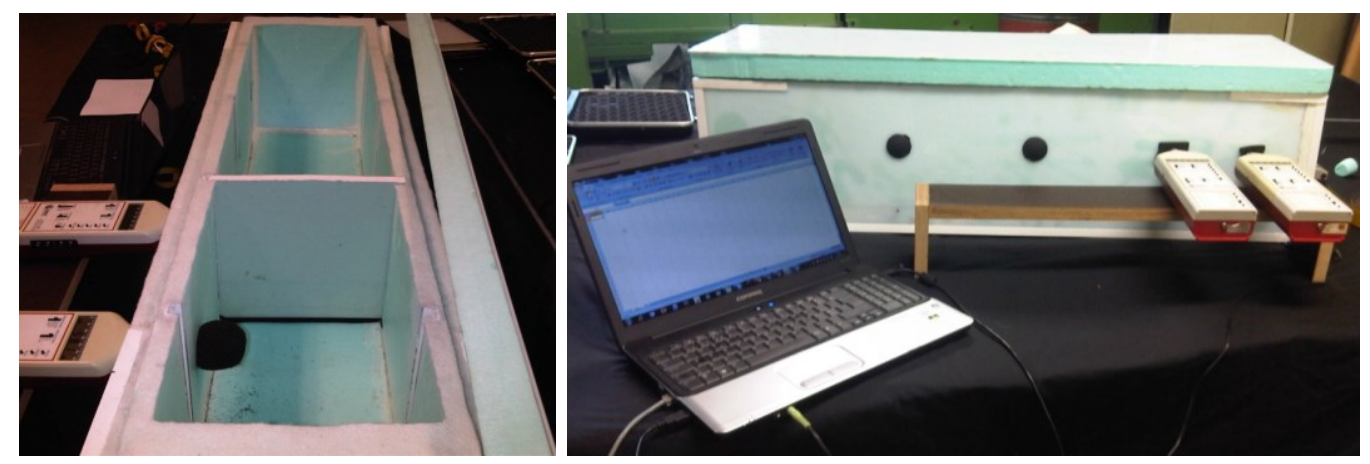

Fig. 6: Interior of sound insulating box (left). Fittings used (right).

This box allowed the evaluation of the reduction of audible noise at different distances between the emitter focus (sound source) and receiver focus. In this present case, the 1st and 2nd position having a distance of $12.5 \mathrm{~cm}$ from each other were used, keeping the sample in the middle of these two positions, (Figure 7).

The audible noise measurement was performed automatically in all bands of octaves ranging from $16 \mathrm{kHz}$ to $31.5 \mathrm{~Hz}$ frequency. Each scanning measurement was carried out for 10 minutes to obtain a large number of measurements. In each scanning, sound level meters acquired and recorded the noise inside the box. At the end, the sound level meters automatically determined the arithmetic mean of the values recorded. In order to disperse any errors caused by externally induced noise, 3 scans were performed for each sample. 


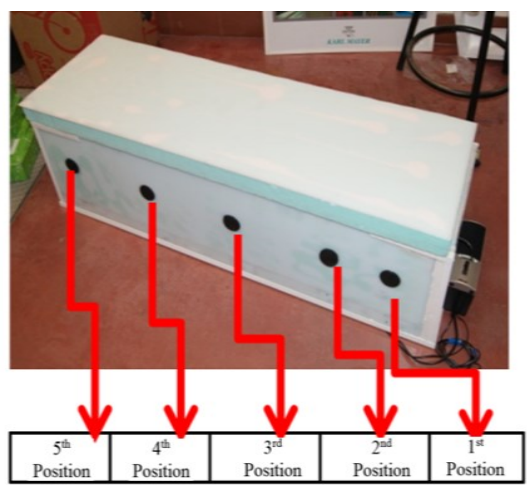

Fig. 7: Identification of the different measurement positions

\section{Obtained Results}

The experimental results obtained within this study are presented in Table 5

Table 5: Noise reduction measured for different samples

\begin{tabular}{|c|c|c|c|c|c|c|c|c|c|c|c|c|}
\hline \multirow[t]{2}{*}{$\mathrm{f}[\mathrm{Hz}]$} & \multicolumn{2}{|c|}{$\begin{array}{c}\text { Panel } \\
\text { 2T9+T2 }\end{array}$} & \multicolumn{2}{|c|}{$\begin{array}{c}\text { Panel } \\
3 \mathrm{~T} 9+\mathrm{T} 2\end{array}$} & \multicolumn{2}{|c|}{$\begin{array}{c}\text { Panel } \\
4 \mathrm{~T} 9+2\end{array}$} & \multicolumn{2}{|c|}{$\begin{array}{c}\text { Plasterboard }+ \\
\text { XPS }\end{array}$} & \multicolumn{2}{|c|}{$\begin{array}{c}\text { Plasterboard } \\
\text { Wall }\end{array}$} & \multicolumn{2}{|c|}{$\begin{array}{c}\text { Plasterboard } \\
\text { Wall }+ \\
\text { Rockwool } \\
\text { Insulation }\end{array}$} \\
\hline & $\begin{array}{c}\mathrm{R} \\
{[\mathrm{dB}]}\end{array}$ & $\begin{array}{l}\text { c.v. } \\
{[\%]}\end{array}$ & $\begin{array}{c}\mathrm{R} \\
{[\mathrm{dB}]}\end{array}$ & $\begin{array}{l}\text { c.v. } \\
{[\%]}\end{array}$ & $\begin{array}{c}\mathrm{R} \\
{[\mathrm{dB}]} \\
\end{array}$ & $\begin{array}{l}\text { c.v. } \\
{[\%]}\end{array}$ & $\begin{array}{c}\mathrm{R} \\
{[\mathrm{dB}]}\end{array}$ & $\begin{array}{l}\text { c.v. } \\
{[\%]}\end{array}$ & $\begin{array}{c}\mathrm{R} \\
{[\mathrm{dB}]}\end{array}$ & $\begin{array}{l}\text { c.v. } \\
{[\%]}\end{array}$ & $\begin{array}{c}\mathrm{R} \\
{[\mathrm{dB}]} \\
\end{array}$ & $\begin{array}{l}\text { c.v. } \\
{[\%]}\end{array}$ \\
\hline $16 \mathrm{k}$ & 30,0 & $3,0 \%$ & 29,2 & $4,4 \%$ & 23,2 & $0,9 \%$ & 27,2 & $6,1 \%$ & 23,4 & $1,1 \%$ & 25,5 & $0,3 \%$ \\
\hline $8 \mathrm{k}$ & 28,0 & $5,4 \%$ & 26,8 & $2,7 \%$ & 22,4 & $0,4 \%$ & 25,7 & $0,7 \%$ & 25,4 & $0,0 \%$ & 26,8 & $0,6 \%$ \\
\hline $4 \mathrm{k}$ & 14,2 & $8,4 \%$ & 14,0 & $2,0 \%$ & 9,8 & $3,8 \%$ & 14,6 & $6,7 \%$ & 18,5 & $5,3 \%$ & 21,9 & $0,6 \%$ \\
\hline $2 \mathrm{k}$ & 12,0 & $10,6 \%$ & 13,7 & $4,7 \%$ & 10,3 & $3,5 \%$ & 11,7 & $7,1 \%$ & 19,9 & $7,2 \%$ & 21,9 & $0,2 \%$ \\
\hline $1 \mathrm{k}$ & 12,2 & $6,0 \%$ & 12,3 & $0,7 \%$ & 8,8 & $5,2 \%$ & 9,7 & $5,5 \%$ & 18,9 & $2,5 \%$ & 21,4 & $1,4 \%$ \\
\hline 500 & 14,2 & $4,7 \%$ & 15,1 & $3,3 \%$ & 12,2 & $2,1 \%$ & 13,5 & $3,1 \%$ & 17,3 & $3,3 \%$ & 20,5 & $1,1 \%$ \\
\hline 250 & 15,8 & $2,4 \%$ & 14,8 & $1,3 \%$ & 14,2 & $2,0 \%$ & 14,9 & $2,8 \%$ & 8,8 & $3,3 \%$ & 9,9 & $3,7 \%$ \\
\hline 125 & 16,5 & $11,5 \%$ & 16,0 & $8,6 \%$ & 14,5 & $14,7 \%$ & 17,8 & $1,6 \%$ & 14,4 & $2,3 \%$ & 15,4 & $2,9 \%$ \\
\hline 63 & 12,7 & $16,1 \%$ & 13,0 & $11,3 \%$ & 12,5 & $7,0 \%$ & 15,8 & $7,5 \%$ & 13,8 & $3,1 \%$ & 14,0 & $1,2 \%$ \\
\hline 31.5 & 0,7 & $113 \%$ & 4,0 & $101 \%$ & 4,0 & $77,5 \%$ & 4,7 & $57,2 \%$ & 7,9 & $36,4 \%$ & 5,9 & $6,2 \%$ \\
\hline
\end{tabular}

In most of the frequencies analyzed coefficient of variation below 5\% was obtained. However, at frequencies below $125 \mathrm{~Hz}$ the coefficient of variation was exceptionally higher. This fact can be attributed to the low level of noise reduction by the sound box at lower frequencies, as well as to the natural difficulty to isolate adequately the test box at these frequencies. However, in some 1 cases, coefficient of variation between $5 \%$ to $10 \%$, has also been noticed

The slightly higher coefficient of variation can also be explained by the externally induced noise. In order to visualize the results more easily, the values obtained as well as its coefficient of variation are shown in Figure 8 which represents the value of sound reduction for each sample as a function of frequency.

Figures 8 show a clear difference between the sound reduction observed in case of sandwich composite panels and "plasterboard wall" solutions with and without insulation. On the other hand, the acoustic insulation behavior of "Plasterboard + XPS" solution was quite similar to the behavior of sandwich composite panels. The difference between the behavior of "panel" and "wall" solutions were noticed mainly in the frequency range of $4 \mathrm{kHz}$ and $500 \mathrm{~Hz}$. All solutions showed superior sound insulation performance at higher frequencies and lower performance at lower frequencies. The noise insulation at the lowest frequency was the lowest value recorded for these specimens. 


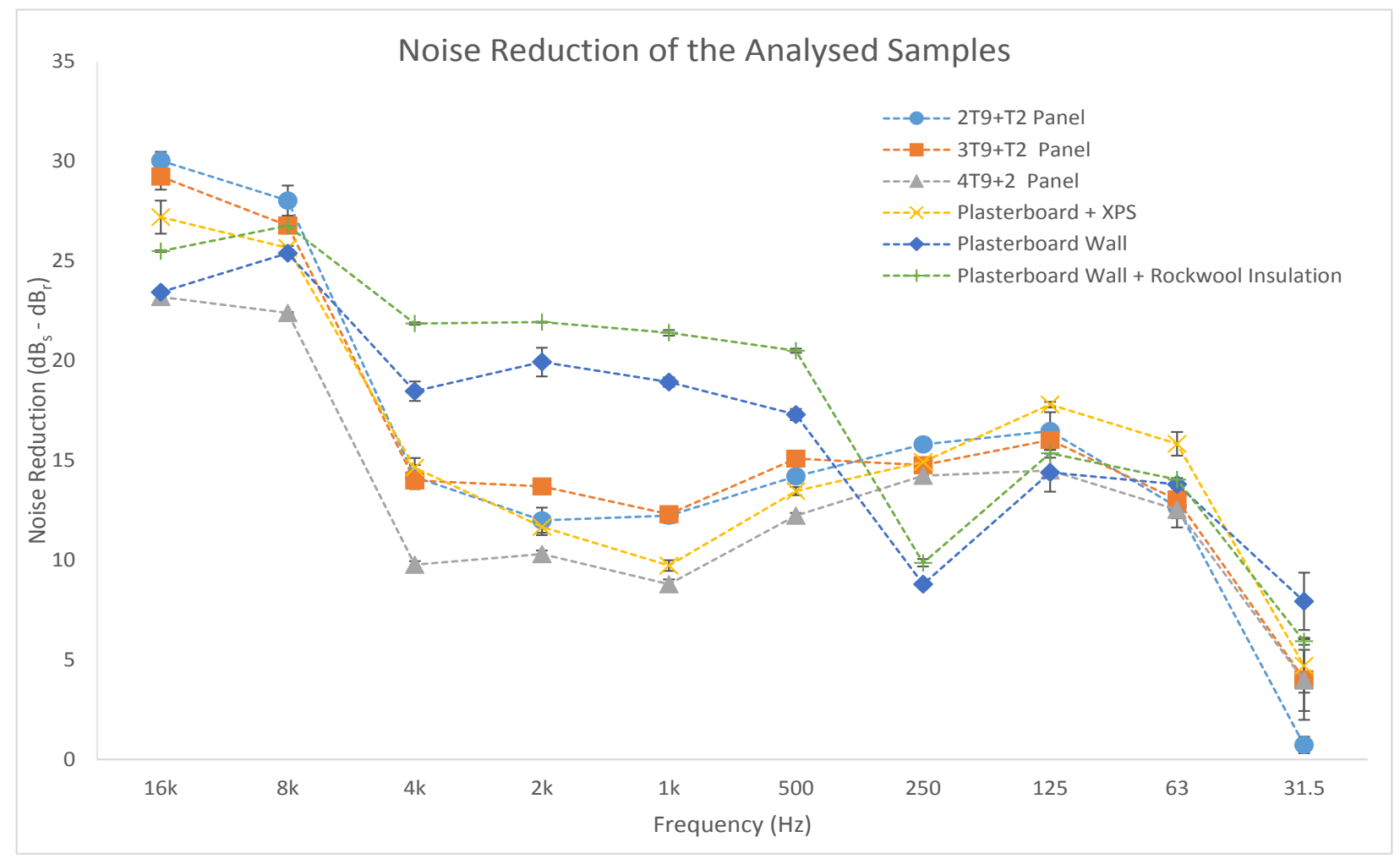

Fig. 8: Noise reduction of the analyzed samples as a function of frequency

\section{Results analysis}

Analyzing only the values of sound reduction obtained for different solutions at various frequencies, it was not possible to make a quantitative comparison of sound insulation of different solutions, and to determine the best solution. For solutions such as plasterboard walls with and without insulation, it was noticed that at higher frequencies the sound insulation was superior to the other solutions; however, at lower frequencies (around $250 \mathrm{~Hz}$ ) the noise insulation was inferior to the other solutions.

So, to quantitatively rank the performance of each solution it was necessary to use the classification proposed in ISO 717-1 and ASTM E413-00 standards in order to calculate the sound reduction index $(\mathrm{Rw})$ of each solution. For this purpose, a reference curve is indicated in each standard that assigns to each frequency at a standard pressure level.

Then, the normalized curve is moved up and down over the experimentally determined noise reduction curve until the average value of unfavorable deviations, (calculated dividing the sum of unfavorable deviations by the total number of frequency bands considered in the test), is the highest possible, but neither exceeding the value of $2 \mathrm{~dB}$, nor exceeding $8 \mathrm{~dB}$ at any frequency .

Noise Reduction Index (Rw) at $500 \mathrm{~Hz}$ frequency for the developed specimens was obtained using the standard curve method, [13]. The values used for the standard curves are listed in Table 6.

Table 6: Reference values used for standard curves

\begin{tabular}{|c|c|c|c|c|c|c|c|c|}
\hline frequency $[\mathrm{Hz}]$ & 125 & 160 & 200 & 250 & 315 & 400 & 500 & 630 \\
\hline Value [dB] & -16 & -13 & -10 & -7 & -4 & -1 & 0 & 1 \\
\hline frequency [Hz] & 800 & 1000 & 1250 & 1600 & 2000 & 2500 & 3150 & 4000 \\
\hline Value $[\mathrm{dB}]$ & 2 & 3 & 4 & 4 & 4 & 4 & 4 & 5 \\
\hline
\end{tabular}

However, as previously mentioned, the sonometer used was only capable of measuring noise in the octave bands of reference, unlike the reference values which present the third octave curves. Thus the quantitative analysis was performed considering only the values in the range of $125 \mathrm{~Hz}$ to $4 \mathrm{k} \mathrm{Hz}$. In Table 7, the values of Rw obtained for each solution, as well as the mean value and sum of the deviations are presented. However, as previously mentioned, the sonometer used was only 
capable of measuring noise in octave bands of reference, unlike the reference values which presents the third octave curve. Thus the quantitative analysis was performed considering only the values in the round of $125 \mathrm{~Hz}$ to $4 \mathrm{k} \mathrm{Hz}$ In Table 7 are presented the values of Rw obtained for each solution, as well the mean value of the deviations and the sum of deviations.

Table 7: $\mathrm{R}_{\mathrm{w}}$ values, maximum deviations and the sum of the deviations observed in all samples.

\begin{tabular}{|c|c|c|c|c|c|c|}
\hline & $\begin{array}{c}\text { Panel } \\
\text { 2T9+T2 }\end{array}$ & $\begin{array}{c}\text { Panel } \\
\text { 3T9+T2 }\end{array}$ & $\begin{array}{c}\text { Panel } \\
\text { 4T9+2 }\end{array}$ & $\begin{array}{c}\text { Plasterboard + } \\
\text { XPS }\end{array}$ & $\begin{array}{c}\text { Plasterboard } \\
\text { Wall }\end{array}$ & $\begin{array}{c}\text { Plasterboard Wall + Rockwool } \\
\text { Insulation }\end{array}$ \\
\hline Sum of Deviations [dB] & 1,93 & 1,67 & 1,52 & 1,83 & 1,76 & 1,49 \\
\hline $\begin{array}{l}\text { Maximum Deviation } \\
{[\mathrm{dB}]}\end{array}$ & 5,00 & 3,70 & 3,23 & 5,27 & 3,53 & 3,13 \\
\hline \multicolumn{1}{|c|}{$\mathrm{R}_{\mathrm{w}}[\mathrm{dB}]$} & 13 & 13 & 9 & 12 & 18 & 20 \\
\hline
\end{tabular}

However, as the literature indicates [13, 14], the reduction of audible noise depends significantly on the surface area of the insulating materials. Therefore, it is also necessary to correlate the noise reduction index with surface area of the different solutions analyzed in this study. The results of this analysis are shown in Figure 9.

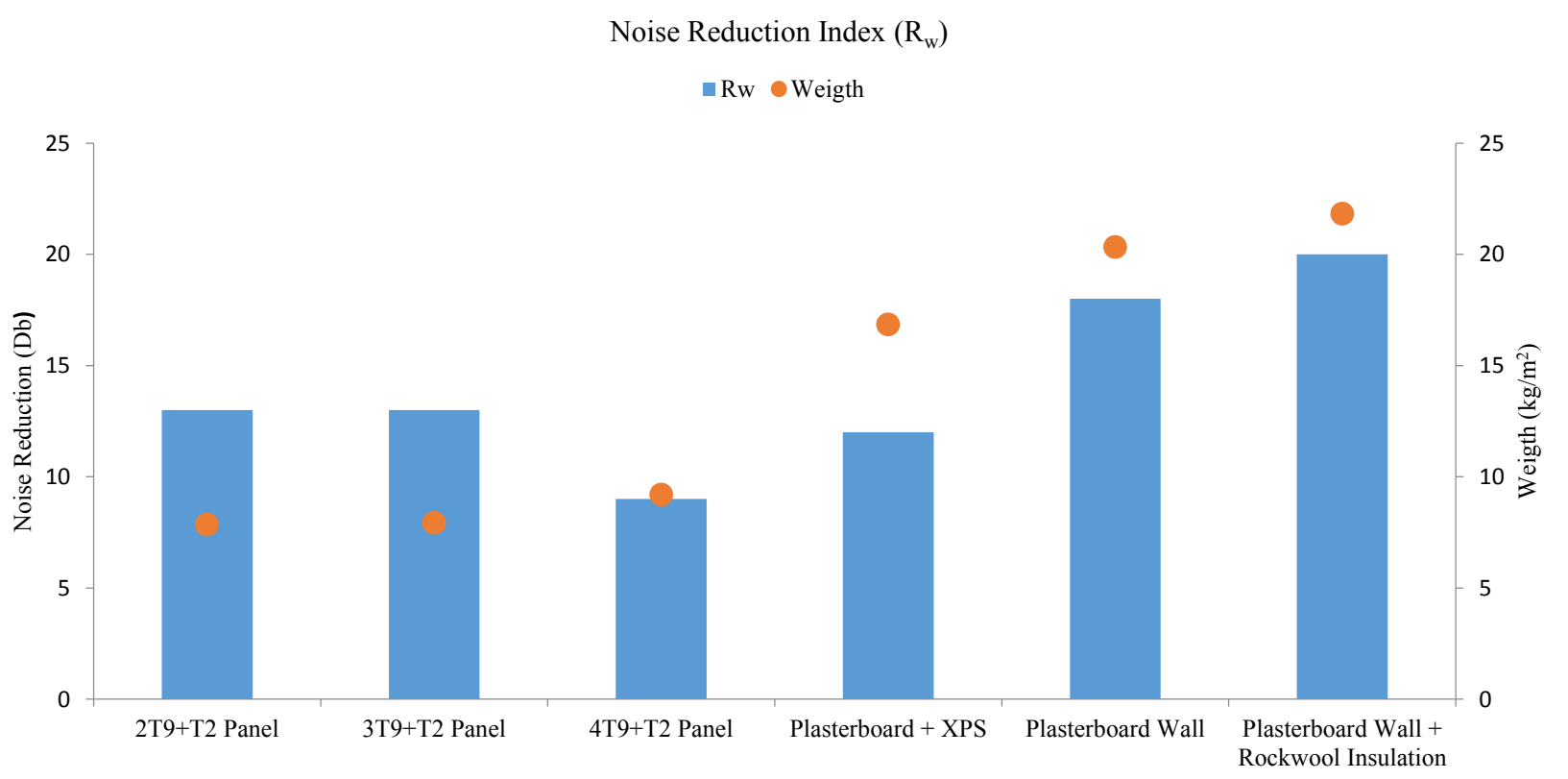

Fig. 9: Noise reduction index of analyzed samples

Thus, from this graph (Figure 9), it is possible to verify that the noise reduction was dependent largely on the mass of the materials; however, in some samples this relationship was not evident. In the case of "4T9 + T2 Panel" with a mass similar to the other hybrid composite panels, the sound insulation was lower by about $4 \mathrm{~dB}$. A similar situation occurred in the case of "plasterboard + XPS" sample for which the mass was about $7 \mathrm{~kg}$ more than the first two samples, but its sound insulation was lower by $1 \mathrm{~dB}$ as compared to the first two solutions.

This type of differences in sound insulation has already been reported by other authors [14]. It was observed in these studies that two elements with the same mass do not necessarily exhibit the same sound insulation. For the materials containing two elements, sound insulation also depends on:

- Existence of air-box: an air-box of $1 \mathrm{~cm}$ allows sound insulation up to $2 \mathrm{~dB}$, while a box-to-air of $5-10 \mathrm{~cm}$ can reduce up to $5 \mathrm{~dB}$;

- Existence of absorbent materials in the air-box: an absorbent material of $1 \mathrm{~cm}$ can provide $1 \mathrm{~dB}$ sound insulation, while with a thickness of 5 to $10 \mathrm{~cm}$ can provide 3 to $4 \mathrm{~dB}$; 
- Difference between materials that compose the walls: for walls made of materials like ceiling tile floors, sound insulation may be up to $4 \mathrm{~dB}$.

Figure 10 shows the specific sound reduction index of different specimens, ie the number of decibels of noise reduction for each kilogram of specimens.

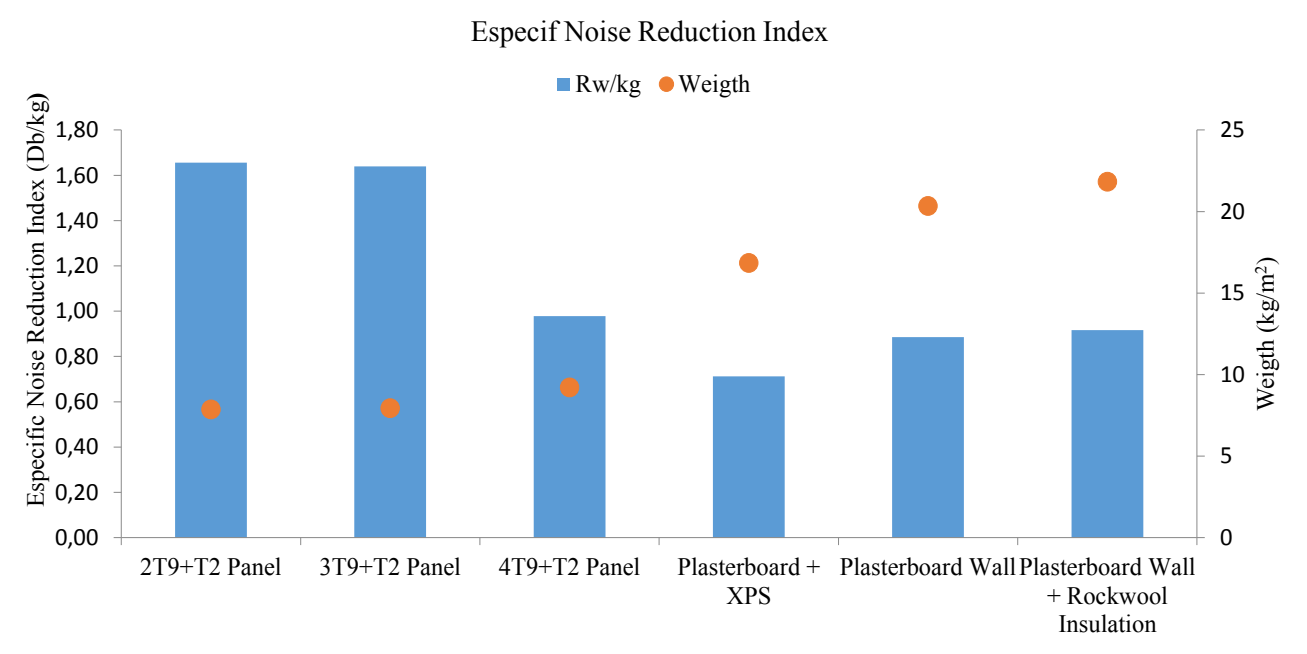

Fig. 10: Specific Noise Reduction Index of analyzed samples

From this graph, it is clear that the specific sound reduction performance of developed sandwich panels was superior to the other samples, i.e, for each kilogram of mass, sandwich panels have superior noise reduction capacity as compared to the other samples.

\section{Conclusions}

It can be concluded that the developed sandwich composite panels with best noise reduction performance 1 were: "Panel 2T9 + T2 "and" 3T9 + T2 Panel "with a sound reduction index of $13 \mathrm{~dB}$ and the solution with the worst performance was "Panel 4T9 + T2 " with a sound reduction index of $9 \mathrm{~dB}$. This fact could be attributed to the lower thickness of XPS panel caused due to increased thickness of the laminated composites without increase in the mass to compensate for the lost thickness of insulation.

However, the same was not true for the samples, "Panel 2T9 + T2 " and "Panel 3T9 + T2 ", where the sound reduction index was the same. The same was concluded when comparing the specific sound reduction index. This difference in behavior was probably attributed to the difference in bonding quality of composite laminates to the XPS core. Since the application of adhesive was done manually, the amount of adhesive applied might not be the same in all samples or even in all areas of same panel, leading to difference in bonding behavior. This fact might have influenced the results.

Moreover, as compared to the developed sandwiched composites, the solutions containing plasterboard i.e. plasterboard wall" with and without insulation have higher level of noise reduction. However, this difference in sound reduction is due to the higher mass per unit surface of these solutions. However, the specific sound reduction index of the developed solutions was higher than the reference solutions. This indicates that if lightness is considered as a determining factor for the performance of these materials for construction application, the developed sandwich composite panels have clear advantage over the reference solutions. 


\section{Acknowledgement}

This work is funded by FEDER funds through the Operational Program for Competitiveness Factors - COMPETE under the project in co-promotion with reference "FCOMP-01-0202-FEDER021581".

\section{References}

[1] L.C. Hollaway; "A review of the present and future utilization of FRP composites in the civil infrastructure with reference to their important in-service properties" Construction and Building Materials journal, 24 (2010) 2419-2445;

[2] S. Patinha, M. M. Morais e P. Cachim; "Construção Modular Casa numa Caixa”, Congresso de Inovação na Construção Sustentável (CINCOS 12), 20 a 22 de Setembro de 2012, Aveiro, Portugal;

[3] P. Santos; "Evolução das Soluções de Parede face a Novas Exigências regulamentares" Seminário sobre Paredes de Alvenaria, P.B. Lourenço et al. (eds.), Laboratório Nacional de Engenharia Civil, 2007, Lisboa;

[4] T. Wang, V. Sokolinsky, S. Rajaram, S. R. Nutt; “Assessment of sandwich models for the prediction of sound transmission loss in unidirectional sandwich panels", Journal of Applied Acoustics 66 (2005) 245-262;

[5] T. Wang, S. Li, S. Nutt; "Optimal design of acoustical sandwich panels with a genetic algorithm" Journal of Applied Acoustics 70 (2009) 416-425;

[6] P. Thamburaj, J. Q. Suno; "Optimization of anisotropic sandwich beams for higher sound transmission loss" Journal of Sound and Vibration (2002) 254(1), 23-36;

[7] C. Ng, C. Hui; "Low frequency sound insulation using stiffness control with honeycomb panels" Journal of Applied Acoustics 69 (2008) 293-30;

[8] H. Wen-chao, Ng Chung-fai; "Sound Insulation Improvement using Honeycomb Sandwich Panels" Applied Acoustics, Vol. 53, No. 1-3, pp. 163-177, 1998;

[9] A. Alves, J. Velosa, S. Patinha, S. Rana e R. Fangueiro; "Development and mechanical characterization of bio-composites for application in light-weight construction", 4th International Conference on Integrity, Reliability and Failure - IRF 2013, Funchal, Portugal, 23 a 27 de Junho de 2013;

[10] S. Patinha, J. Velosa, A. Alves, S. Rana, R Fangueiro; "Comparison Of Flexural Properties of Biocomposites and Plaster Board Panels", 1st International Conference on Natural Fibers - ICNF 2013, 9 a 11 de Junho 2013 Guimarães, Portugal;

[11] R. Carvalho, S. Rana, R. Fangueiro and F. Soutinho; "Noise reduction performance of hermobonded nonwovens" 12th World Textile Conference AUTEX 13 a 15 de Junho 2012, Zadar, Croacia;

[12] Surajit Sengupta; "Sound reduction by needle- punched nonwoven fabrics", Indian Jornal of Fibre \& Textile Research, Vol. 35, September 2010, pp. 237-242;

[13] Ana Ferreira; "Soluções Técnicas para Isolamento Sonoro de Edifícios de Habitação", Tese de Mestrado, Instituto Superior Técnico, Universidade Técnica de Lisboa, Outubro, Lisboa, Outubro, 2007.

[14] Gonçalo Tomaz Lopes Almeida, "Análise de Soluções Construtivas para a Verificação de Requisitos Térmicos e Acústicos em Edifícios de Habitação", Tese de Mestrado, Universidade Nova de Lisboa, Faculdade de Ciências e Tecnologia, Lisboa, 2009. 


\section{Sustainable Construction Materials}

10.4028/www.scientific.net/KEM.634

Acoustical Behavior of Hybrid Composite Sandwich Panels

10.4028/www.scientific.net/KEM.634.455 